\title{
Uma Metodologia para Implementação da Disciplina Informática Básica em Cursos Técnicos Integrados ao Ensino Médio
}

\author{
Lafayette Batista Melo ${ }^{1}$, Paulo Roberto Santos $\operatorname{Costa}^{1}$, Marcílio de Paiva Onofre \\ Filho $^{1}$, Fernando Augusto Ferreira Lordão ${ }^{1}$, Leandro Cavalcanti de Almeida ${ }^{1}$ \\ ${ }^{1}$ Unidade Acadêmica de Informática - Instituto Federal da Paraíba (IFPB) \\ CEP 58.015-435 - João Pessoa - PB - Brazil \\ \{lafagoo, prbcosta, marcilionofre\}@gmail.com, ffernando.lordao, \\ leandro.almeida\} \&ifpb.edu.br
}

\begin{abstract}
This article shows how the discipline of "Basic Computing" was reconstructed for technical courses integrated to high school, employing a methodology that involves: 1) Internet search with advanced techniques; 2) consultation of the vision of managers, teachers and students through a questionnaire; 3) confrontation of 1 with 2 for analysis and categorization of what is up and down in the discipline; 4) research about educational methodologies and technologies and 5) reconstruction of the teaching plan and training of multiplier teachers. The first group of students accepted the new version of the discipline well and the multiplier teachers are employing most of the strategies learned.
\end{abstract}

Resumo. Este artigo mostra como foi reconstruída a disciplina de "Informática Básica" para cursos técnicos integrados ao ensino médio, empregando uma metodologia que envolve: 1) busca na Internet com técnicas avançadas; 2) consulta da visão de gestores, professores e discentes através de um questionário; 3) confronto de 1 com 2 para análise e categorização do que está em alta e em baixa na disciplina; 4) investigação de metodologias e tecnologias educacionais e 5) reconstrução do plano de ensino e capacitação de professores multiplicadores. A primeira turma de alunos aceitou bem a nova versão da disciplina e os professores multiplicadores da capacitação estão empregando a maioria das estratégias aprendidas.

\section{Atualidade da Disciplina Informática Básica e sua Necessidade de Mudança}

A disciplina "Informática Básica", oferecida aos cursos técnicos integrados, dá subsídios para uso do computador e de seus programas de modo que o aluno seja mais produtivo academicamente e profissionalmente. Este componente curricular encontra-se em uma situação peculiar devido às mudanças tecnológicas e à própria evolução da Informática, o que faz com que se questione quais conteúdos devem ser dados e de qual maneira, sua atualização, e os subsídios concretos para a formação do aluno. Além disso, há dúvidas sobre se o que está sendo ensinado é útil ou mesmo se não é dispensável, pelo fato de o alunado fazer parte de uma geração impregnada de tecnologia e supostamente já ser detentora do conhecimento de Informática, às vezes até maior do que o dos professores. 
Um parâmetro para vislumbrar a disciplina no contexto histórico atual é o estudo do comportamento das gerações, conforme Cordoni (2016). A autora caracteriza as classes genealógicas da seguinte forma: a geração X (nascida de 1960 a 1980) é competitiva profissionalmente, individualista e, apesar de ser a primeira que teve contato com o computador, é a mais resistente às novas tecnologias; a geração Y (1980 a 2000) é otimista, comprometida, multitarefa e totalmente conectada às novas tecnologias - cresceram com as interfaces gráficas (que usam mouses e janelas de aplicação) e são dependentes da Internet para realizar suas tarefas; a geração Z (2000 a 2009) é a composta pelos "nativos digitais", é imediatista e tem preocupações ambientais; e a geração Alpha (2010 em diante) é curiosa, independente e é formada por indivíduos que são conectados bem antes de serem alfabetizados.

Atualmente, uma grande parte de professores de Informática Básica é formada pela geração $\mathrm{X}$ e a maior parte dos alunos é constituída pela geração Y. Isso é perpassado pelo olhar de professores $X$, que ainda se comportam como usuários passivos, ao contrário dos alunos $\mathrm{Y}$. Mesmo que professores $\mathrm{Y}$ surjam, há ainda as gerações $\mathrm{Z}$ e Alpha que aparecem com novos comportamentos a serem enfrentados. Enfim, a revisão de conteúdos de "Informática Básica", o estudo de novos procedimentos e estratégias de ensino são fatores chave para que a disciplina tenha seu status renovado e com importância ainda maior para as novas gerações.

Adiante, na Seção 2, são analisados alguns trabalhos com diferentes aplicações de Informática no ensino médio e técnico. Isso não pode ser desvinculado das condições e das possibilidades dos cursos técnicos integrados dos Institutos Federais. É por isso que este relato de experiência mostra a realidade atual que é refletida nos planos de curso, conforme colocado na Seção 3. A Seção 4 descreve investigação sobre as visões que gestores, professores e discentes têm da disciplina, pois tais atores não só são imprescindíveis nesta pesquisa, mas têm representantes de diferentes gerações. A Seção 5 destaca sugestões de conteúdo, estratégias de ensino e o desenvolvimento da disciplina. Na Seção 6, temos algumas constatações e recomendações gerais.

\section{Trabalhos relacionados}

Trabalhos com as especificidades para construção de uma disciplina de Informática Básica, dos cursos técnicos integrados ao ensino médio de Institutos Federais, não foram encontrados, mas algumas abordagens, em um ou outro aspecto relacionado, ajudam a delinear uma metodologia de revisão da disciplina.

Machado (2010) trata da necessidade de inserir o jovem no mercado e de como a Computação é uma oportunidade muitas vezes perdida. Os estereótipos e preconceitos que circulam na escola dificultam a escolha da área como uma alternativa profissional. O autor parte das referências da Olimpíada Brasileira de Informática e da Computação desplugada para criar um projeto de descoberta de novos talentos em Computação. São chamados alunos para turmas específicas que aprendem programação em linguagem $C$, mas com dinâmicas que envolvem também a ferramenta Scratch. Acreditamos que, no ensino médio e na nossa realidade, é exatamente na disciplina de Informática Básica que uma atividade desse tipo deve ser feita. É nesse momento que muitos dos estereótipos podem ser mais rapidamente desconstruídos, sem contar a divulgação da Computação. 
Marques (2017) lida com um projeto de curso técnico em Informática integrado ao ensino médio, mas especificamente direcionado para melhorar o pensamento computacional dos estudantes de modo a facilitar o aprendizado nas disciplinas de programação. $\mathrm{O}$ autor utilizou jogos de tabuleiro e problemas de lógica em encontros que davam apoio a alunos que estavam fazendo a disciplina Programação I. O projeto obteve sucesso, mas era algo extra à disciplina e unicamente direcionado à melhoria de programação sem abordar o que uma disciplina de Informática Básica poderia tratar.

Brum (2017) tem uma preocupação especial com as novas gerações, incluindo os nativos digitais, o que faz com que direcione uma disciplina optativa de robótica para a educação básica, utilizando conceitos de gamificação. $O$ trabalho envolve distribuição de tarefas com o cuidado de usar a linguagem da geração de nativos digitais (por exemplo, "time" em vez de "grupo" ou "equipe") e divisão bem demarcada das ações de cada elemento do time de modo que todos participem colaborativamente.

Godinho (2017) trata de um projeto para incentivar crianças e jovens em atividades de programação através de jogos em várias escolas. Para tanto, adota oficinas e minicursos com muitas plataformas de jogos para só depois entrarem no uso de ferramentas como Scratch e App Inventor. As atividades obtiveram alta aceitação da população e satisfação dos alunos, mas o planejamento envolvia decidir quais tarefas realizar com cada grupo infantil ou juvenil e a estrutura da escola.

Aono (2017) realiza uma pesquisa aplicada ao sexto ano do ensino fundamental com uso de Scratch, mas também discute o uso da ferramenta no ensino médio em uma ampla revisão bibliográfica, constatando que a distribuição de aulas práticas e teóricas, lançamentos de desafios e desenvolvimento de jogos devem ser igualmente pensados, mas com planejamento totalmente direcionado para as dificuldades de cada turma.

Pode-se notar que há pesquisas quantitativas e qualitativas, experiências, aplicação de oficinas e minicursos, apoiando ou não disciplinas de Informática (em geral, de programação), com direcionamento ao ensino médio e técnico e até o médio integrado ao técnico, mas não em uma disciplina de Informática Básica. Considerando os cuidados e orientações dos demais trabalhos, acreditamos que propostas de apoio, incentivo, divulgação, desmistificação e melhoria de aprendizagem em Computação podem ser fundidas em uma disciplina deste tipo, mas não sem antes investigarmos as possibilidades e necessidades de cursos técnicos integrados ao médio, em um planejamento que contemple a realidade institucional e as vontades das várias gerações envolvidas. É por isso que adiante vamos relacionar a realidade atual da disciplina em seus planos de ensino com o que estão pensando gestores, professores e alunos.

\section{A Realidade Atual dos Planos de Ensino da Disciplina}

Para investigar como a disciplina "Informática Básica" está sendo desenvolvida nos cursos técnicos integrados, através de seus planos pedagógicos de curso, foi realizada uma pesquisa com os seguintes passos:

1. Verificação, através do Google, de planos de curso da disciplina, utilizando palavras-chave e comandos avançados do Google Search. Exemplos: "plano de curso" "Informática Básica" "curso técnico integrado" - nesse caso, para obter planos da disciplina diretamente nos resultados de busca, clicando neles e baixando 
o documento quando for adequado; "Instituto Federal" "plano de curso" "Informática Básica" - do mesmo modo, para uma pesquisa mais ampla do que a anterior, que poderia não incluir "curso técnico em", "plano do curso técnico em Informática" filetype:pdf - para obter os documentos mais comuns no formato PDF; etc.

2. Leitura dos planos, especialmente as ementas.

3. Coleta dos links, da descrição das ementas dos cursos e endereços na Web onde estão os documentos - uso da ferramenta Linkclump (https://chrome.google.com/webstore/detail/linkclump/lfpjkncokllnfokkgpkobnkbk melfefj);

4. Registro dos $\mathbf{1 0 0}$ primeiros resultados de pesquisa coletados em uma planilha do Google Docs - no endereço https://docs.google.com/spreadsheets/d/1j39XdhzOQ0Hk976RYsvEV7aXGQOEC F_hFOmzaQJTjGM/edit\#gid=0;

5. Geração de uma nuvem de palavras com os termos usados nas ementas dos cursos - para verificar possíveis conceitos e assuntos que são mais tratados em todos os planos das disciplinas - uso da ferramenta Wordclouds.com: https://www.wordclouds.com/

Resultados das pesquisas são resumidos adiante, com os dados mais relevantes.

Em relação ao conteúdo das disciplinas - As ementas se baseiam em tipo de software, componentes de hardware, uso de editor de texto, planilha e softwares de apresentação. Ao final, algumas acrescentam tópicos referentes ao curso técnico (se for um curso médio integrado ao técnico). Algumas falam de ambientes virtuais de aprendizagem (quando são feitas a distância). Mesmo os cursos de ensino médio integrados ao técnico na área de Informática têm "Introdução à Informática" com uso de aplicativos, história da Internet, uso de utilitários, aplicativos e sistemas operacionais.

Em relação às referências bibliográficas adotadas - Usam muita referência bibliográfica antiga (de 2002, 2003, 2004) mesmo em cursos de 2014 até hoje.

Nomenclatura - A maioria é "Informática Básica", mas tem "Introdução à Informática", apenas "Informática" e "Ambientes virtuais e Informática". Algo como "Informática Aplicada" não foi observado.

Metodologias de ensino - Nenhum plano fala de métodos novos ou aplicação de software para o ensino; são tradicionais com "aulas expositivas" e com acesso a computador e à Internet.

Objetivos dos planos - Os principais objetivos ainda são operar softwares básicos e aplicativos.

O que indicam as pesquisas - Em uma busca no Google com "Instituto Federal" plano "Informática Básica" -técnico -integrado filetype:pdf", que quer dizer use esses 3 primeiros termos e exclua "técnico" e "integrado" da pesquisa para encontrarmos só arquivos PDF, o resultado ainda é muito grande com cursos técnicos integrados ao médio. Verificar ementa de cursos exclusivamente do ensino médio, sem técnico foi muito difícil. Tentou-se várias combinações e todas elas tinham o mesmo 
problema. Esses resultados sugerem que os ensinos médios integrados aos técnicos têm uma tendência grande de serem os que mais requisitam a disciplina.

Foi feita uma nuvem de palavras das ementas com o Wordclouds.com, para vislumbrar melhor, de uma forma panorâmica, comprovar resultados anteriormente obtidos e identificar ainda outras possíveis peculiaridades, conforme a Figura 1.
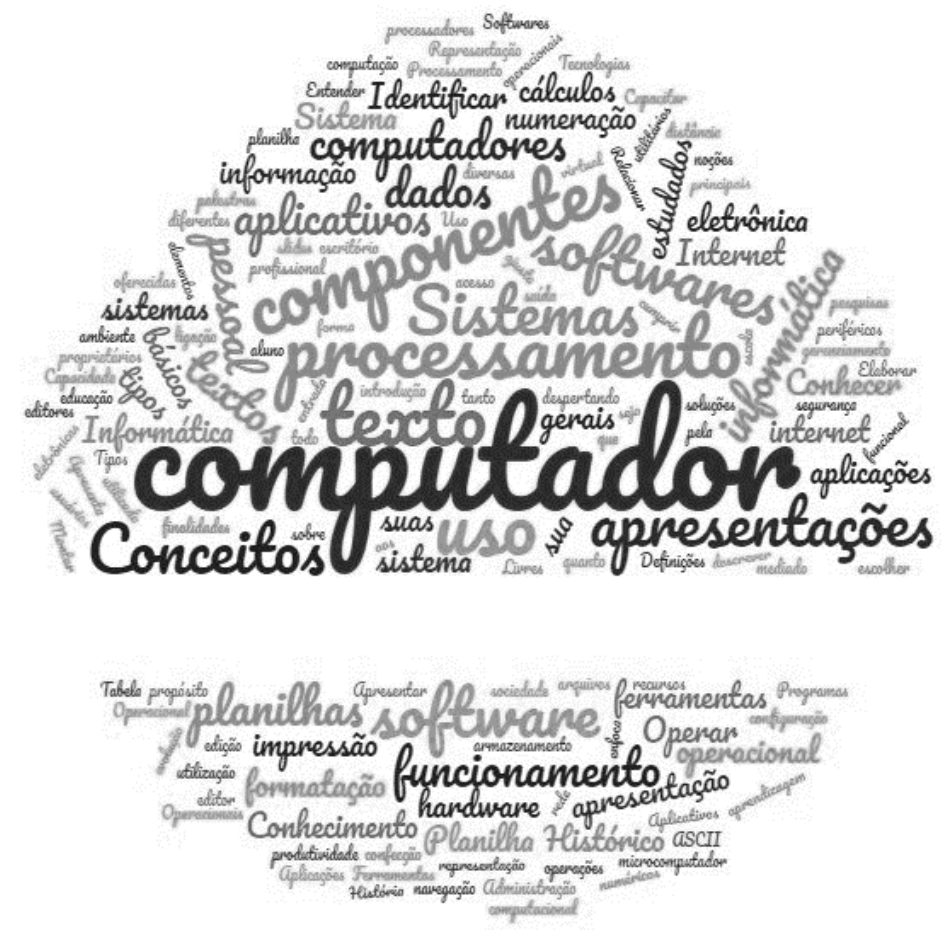

Figura 1 - nuvem de palavras com termos das ementas

Comprovou-se não só que o conteúdo dado é ainda tradicional, de acordo com as ementas, mas que provavelmente é ainda fixo e pouco muda. Por exemplo, discussão sobre histórico do computador ainda é importante embora pareça ocupar menor espaço que antigamente. Uso de aplicativos (editor de texto, planilha e software de apresentações) continuam unanimidade, bem como menção aos componentes de hardware. Sistemas numéricos têm uma tendência a aparecer cada vez menos. Administração, segurança e produtividade parecem ser assuntos pontuais que, embora não ocupem grande parte da carga horária do curso, surgem mais recentemente.

\section{A Visão de Gestores, Docentes e Discentes}

Foi constituída uma comissão para revisão da disciplina de "Informática Básica" tanto para a investigação da realidade atual em vários planos do Brasil, como mostrado anteriormente, quanto para consulta com os vários atores institucionais em reuniões departamentais de todos os cursos técnicos integrados ao médio. Aplicaram-se questionários com gestores (que devem conhecer melhor a realidade administrativa da instituição e dos cursos), com docentes (que podem mostrar suas limitações e aplicações de novos conhecimentos) e com discentes (cujas necessidades e motivações acreditamos que devem ser sondadas, especialmente se os confrontamos com atores de outras gerações). Utilizou-se o Google Docs para aplicar o questionário on-line em 
formulários, mas com horários específicos para cada turma ou reunião em laboratório, de modo que tivéssemos exatamente as reais pessoas envolvidas de cada grupo.

A pesquisa feita com os gestores envolveu uma quantidade menor de atores e as perguntas envolviam saber sua função, área, curso, expectativas sobre a disciplina, visão dos alunos, conteúdo e ferramentas a serem usados. Todos os gestores tinham a função de coordenadores de curso. Ressalta-se a pergunta sobre o que deveria ser melhorado na disciplina, com uma quantidade de respostas maior relacionada à infraestrutura, algo que não pertence à esfera de poder da comissão com a nova proposta, mas que pode ser cobrado institucionalmente. Ao menos orientou-se para refletirmos no uso ou não de ferramentas gratuitas. Como responderam apenas coordenadores de cursos técnicos integrados ao médio, as respostas sobre o conteúdo a ser aplicado variaram muito, com referência a marketing virtual, mídias sócias, Arduíno, iniciação a programação e planilhas; algo certamente relacionado à realidade de cada curso

Em relação aos docentes, as perguntas relacionadas envolviam conteúdos que deveriam continuar na nova versão da disciplina com os assuntos: conceitos básicos (definição e classificação de hardware e software foram citados por todos os professores); sistemas operacionais (gerenciamento de arquivos e pastas e configuração básica foram lembrados por 83\%); Internet (uso de e-mails citados por 100\%); edição de textos (os mais mencionados com cerca de $80 \%$ foram edição básica, formatação e uso de tabelas e figuras); planilhas (com ocorrência de edição de tabelas e gráficos); e noções gerais - nesse caso "aplicativos da área de cada curso" foram mencionados por todos os professores em detrimento de redes de computadores $(50 \%)$ e redes sociais (25\%). Sobre os conteúdos a incluir, os escolhidos com maior frequência foram noções de programação com Scratch ou App Inventor (100\%), cidadania e segurança na Internet $(66 \%)$ e armazenamento em nuvem (66\%). A maior dificuldade descrita pelos professores em questão aberta foi a heterogeneidade de conhecimento dos alunos.

O questionário com os alunos foi mais amplo, juntando o $2^{\circ}, 3^{\circ}$ e $4^{\circ}$ anos de alunos que já haviam feito a disciplina, em um total de 158 alunos de cursos técnicos integrados ao médio. As perguntas foram semelhantes às feitas aos professores e os resultados foram também muito parecidos. Em relação a quais conteúdos deveriam continuar, a ampla maioria citou edição de texto, planilha e programas de apresentação. Sobre quais conteúdos deveriam ser retirados, a maior incidência de respostas foi "nenhum conteúdo deve ser retirado", com mais de 60\%, mas algumas citações sobre histórico do computador ficaram em menos de $10 \%$, enquanto que outros conteúdos foram citados de forma mais dispersa com pouco percentual. Sobre quais conteúdos deveriam ser inseridos, programação teve cerca de $40 \%$ de incidência, mas com muitas variações (Python, C, Arduíno, C++, Scratch e etc.). Também apareceram respostas como "ABNT". É importante salientar que, diferentemente da pesquisa junto aos docentes, o questionário com os alunos foi feito com respostas abertas e certamente por conta disso houve tanta variação. Mesmo assim, há coincidência com os professores, principalmente em relação a quais assuntos deveriam continuar. As maiores reclamações dos alunos estão relacionadas à superficialidade dos assuntos e dinâmica das aulas, embora não queiram mudar os assuntos, e a necessidade de uma ementa mais direcionada ao curso, com variações conforme a área e a familiaridade dos alunos. 


\section{Conteúdo, Estratégias de Ensino e Desenvolvimento da Disciplina}

Confrontando o levantamento dos planos de curso com a consulta feita a professores, gestores e alunos, bem como a experiência dos autores desta pesquisa, que também constituíram a comissão de revisão, o plano foi reformulado, mas houve nova reunião com as coordenações para que se mostrasse a necessidade de haver professores que tivessem algum conhecimento específico ao final do período. Isso aconteceu em decorrência de, apesar de os planos não fazerem este tipo de referência, haver uma preocupação de todos os atores da instituição. O gerenciamento da disciplina é feito pela área de Informática com os cuidados descritos a seguir nas próximas Sub-Seções.

Antes, porém, é importante que mostremos uma fase intermediária da implementação que consiste em listagem e categorização do que está em alta e em baixa para o desenvolvimento do curso, considerando todos os dados obtidos e o que poderia ser implementado no momento atual, conforme a Figura 2.

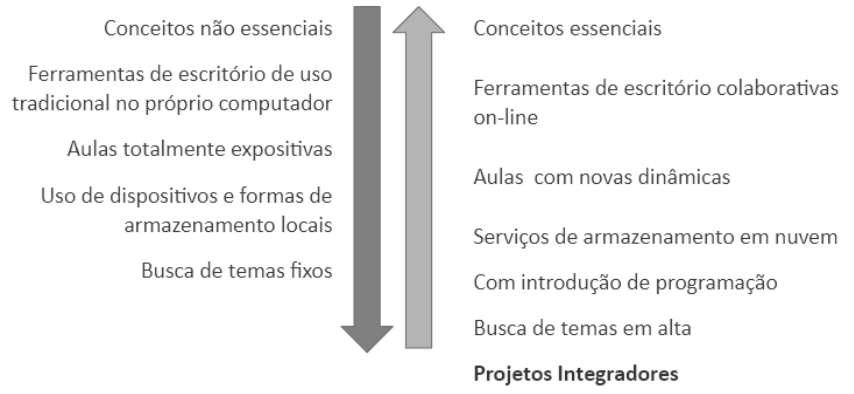

Figura 2 - o que está em alta e em baixa na disciplina Informática Básica

Em relação ao que está em baixa, consideramos conceitos não essenciais que poderiam ser retirados no momento, por não terem seguimento na própria disciplina ou por já serem abordados em outros componentes curriculares ou já serem de conhecimento do aluno como conversão numérica e classificações exaustivas de tipos de software e hardware. Dentro de conceitos em alta, consideramos que menções históricas ainda devem ser tratadas, mas de forma mais reduzida e com outra forma de apresentação. Uso de aplicativos, por exemplo, ainda é algo referido por todos como importante, mas exatamente o que deve ser trabalhado demanda investigar as necessidades atuais da turma. Em baixa, está o uso de aplicativos específicos de escritório ainda apenas instalado no próprio computador. Alunos já usam muita edição de textos nas nuvens e pacotes deste tipo são oferecidos gratuitamente para o ensino. Isso não quer dizer que nada de edição de texto e planilhas em desktop deva ser mencionado, pois em empresas e em várias submissões de documento ainda são requeridos formatos DOC ou PDF, por exemplo. A solução aqui é priorizar pacotes nas nuvens, que inclusive são usados em convênios com instituições de ensino, como o Google For Education, mas sempre orientando os professores para mencionarem as diferenças em relação ao uso único no computador. As aulas apenas expositivas e com exercícios estão em baixa, mas há possibilidades de se incluir outras estratégias e até ferramentas para dinamizar as aulas, as quais devem ser pesquisadas a cada edição da disciplina devido às mudanças e disponibilidade. Uso apenas de dispositivos de armazenamento de massa, como eram antigamente tratados, como $\mathrm{CD}$ e disquete não fazem mais sentido atualmente. O pendrive também está cedendo para armazenamento nas nuvens, cujos alcances devem ser esclarecidos para os alunos, seja para edição de 
documento em conjunto, controle de versões, formas de conversão entre outas possibilidades, incluindo o gerenciamento móvel. Imaginar que a busca por temas consagrados e fixos devam ser um intuito em disciplinas como essa parece ser algo a fugir da realidade. Uma inspeção com professores e coordenações de curso, bem como com os alunos, para atualização constante da ementa é algo que se faz extremamente necessário. Neste período, procuramos inserir, como sugerido pelos participantes, discussões temáticas e dicas sobre cidadania digital, segurança e privacidade em redes sociais. A inserção da programação se faz necessária exatamente nesta disciplina, pois é um instante do curso que abre o aluno para várias possibilidades do uso da Informática, e que é premente hoje em dia para inserção do pensamento computacional. Isso não quer dizer que haverá um aprofundamento em programação, mas a inserção de noções de forma lúdica e sempre voltada para um passo posterior no curso técnico. A ideia de projetos integradores nos documentos de referência dos cursos técnicos integrados ao médio parece ocorrer em um momento oportuno para conversar com professores de todos os cursos e direcionar, por exemplo, até mesmo os aprendizados iniciais de programação. Vejamos como fizemos a primeira implementação da nova proposta.

\subsection{Conteúdo}

No primeiro ano do ensino médio, com carga horária de $66 \mathrm{~h}$ e duas aulas por semana, com a seguinte distribuição:

$1^{\mathrm{o}}$ Bimestre - Introdução à Informática - utilizamos um convênio da nossa instituição com uma empresa de renome que faz treinamentos a distância em ambientes virtuais especializados e colocamos isso como proposta para os alunos. O conteúdo trata ainda de histórico e tipos de hardware e software, mas com testes virtuais e acompanhamento que possibilita um certificado para conclusão da etapa. As aulas são feitas em grande maioria no formato de sala de aula invertida, para discutir o que os alunos estudaram no ambiente, e nesta etapa mais de $90 \%$ de uma turma já obteve o certificado. O uso desse ambiente e do convênio será sempre reavaliado.

$2^{\circ}$ Bimestre - Ferramentas colaborativas, utilizando como exemplo o Google For Education que também foi cadastrado para a instituição. Além das diferenças de usar programas apenas para o próprio computador, são feitos desafios para as equipes em cada aula para construção, por exemplo, de artigos ou formulários. Mostra-se o que há ainda de limites nas nuvens, que só com as ferramentas desktop pode ser realizado, mas também como extensões ao browser e complementos nas diferentes aplicações já inserem possibilidades novas como sumário, cores, gerenciamento de figuras, geração de nuvens de palavras, contagem de palavras, formas de compartilhamento e rastreamento de dados etc.

$3^{\circ}$ Bimestre - Fundamentos de programação - utilizamos o Scratch para iniciar programação com os cuidados descritos na Seção de trabalhos relacionados, mas voltando-se para resolver um problema específico do curso técnico integrado ao médio, cuja discussão é feita antes com as coordenações, podendo se iniciar projetos de robótica até contabilidade empresarial, conforme o que vão requerer antes os participantes.

$4^{\circ}$ Bimestre - Programação para Mobile - utilizamos o App Inventor, do MIT, que tem conceitos básicos de programação, continuando o que foi aprendido com o 
Scratch, mas desbravando as possibilidades dos dispositivos móveis que vão desde a construção de aplicativos simples para acionar música com o movimento do celular até construção de jogos que associem figuras a textos, sons e animações, cujo conteúdo cada aluno poderá direcionar conforme seu interesse e o do curso.

\subsection{Tecnologias e Metodologias de Ensino}

Além de trabalharmos com a ideia de aula invertida para alguns conteúdos, fazermos propostas e desafios, utilizamos tecnologias que possibilitam discutir ou testar conceitos rapidamente (por exemplo, após o estudo de conceitos do $1^{\circ}$. Bimestre ou após explanação em laboratório de conceitos de programação no $3^{\circ}$. e $4^{\circ}$. Bimestres). Essas tecnologias de testes rápidos em sala ou laboratório possibilitam uso de celular nas aulas e o professor pode produzir vários tipos de teste configurável. Um exemplo é a criação de testes com sete perguntas de marcar, cada uma com uma cronometragem, mostrando a pontuação dos alunos (medida pela resposta certa e tempo de resposta), com a posição final de cada um após o desafio. Isso possibilita rever conteúdo, tirar dúvidas e criar novas dinâmicas de interação professor-aluno e aluno-aluno. As ferramentas que usamos para produção dos testes e compartilhamento, reuso e modificação entre os próprios professores são o Kahoot ${ }^{1}$ e o Quizziz ${ }^{2}$.

\subsection{Plano de Ensino}

A disciplina continuou com o nome de "Informática Básica", pois o que se quer aplicar mais na disciplina ao seu final é conteúdo dos cursos para desenvolvimento do próprio conteúdo de Informática Básica, além de a grande maioria de cada um dos grupos de atores institucionais estarem todos em concordância sobre o desenvolvimento de conteúdos básicos, embora com nova extensão. Procurou-se distribuir planos com professores, tratando também das metodologias usadas, algo que não foi verificado nos planos anteriores, mas que parece enriquecedor.

\subsection{Capacitação de Professores}

Em conjunto com a aplicação do plano de forma sistematizada neste período - em períodos anteriores ocorreram experiências esparsas - foi realizada uma capacitação com sete professores de cada um dos cursos técnicos integrados ao médio. A capacitação trata do modo como conteúdo e estratégias são desenvolvidas, mas também é um espaço de consulta com os professores multiplicadores de detalhes do programa e sugestões adicionais para cada um dos cursos técnicos. Também obtivemos relatos de como estão aplicando o aprendido ao desenvolverem as disciplinas no período atual.

\section{Algumas Constatações e Recomendações Gerais}

Ao implementarmos a disciplina por meio de uma nova metodologia, pretendemos responder a questionamentos que incluem abordar ou não certos conteúdos, mas não só isso. Também norteamos sobre procedimentos pedagógicos, comportamentos, atitudes,

\footnotetext{
${ }^{1}$ https://kahoot.com/

${ }^{2}$ https://quizizz.com/
} 
metodologias e tecnologias de ensino que são tão caras para as gerações que se relacionam hoje em dia e que precisam de novos enquadramentos e formas de interação para um melhor aproveitamento acadêmico e profissional.

Outra contribuição deste trabalho está na própria metodologia de investigação para revisão, modificação e aplicação da nova versão do componente curricular, a qual podemos descrever nos seguintes passos: 1) busca na Internet com ferramentas de pesquisa e estratégias avançadas de busca de planos pedagógicos semelhantes; 2) consulta da visão de gestores, professores e discentes através de um questionário sobre o atual desenvolvimento da disciplina; 3) confronto de 1 com 2 para análise e categorização do que está em alta e em baixa na disciplina; 4) investigação de metodologias e tecnologias educacionais atuais a serem adequadas especificamente para o novo conteúdo; 5) reconstrução do plano de ensino e capacitação de professores multiplicadores das disciplinas para atuarem de forma direcionada nos cursos técnicos integrados ao médio.

Tanto no estudo de aplicação sistemática da disciplina no ano atual quanto na capacitação dos professores, alunos e discentes têm respondido muito bem à mudança, com questionamentos apenas pontuais e eventuais sobre o nível de detalhamento dos conteúdos. Pretende-se em trabalhos futuros fazer uma pesquisa ampla sobre os vários anos de aplicação da nova disciplina de "Informática Básica" bem como replicar o método de investigação para revisão e mudança de outros componentes curriculares em Computação, verificando possíveis adequações.

\section{Referências}

Aono et al. (2017) "A Utilização do Scratch como Ferramenta no Ensino de Pensamento Computacional para Crianças", In: Anais do XXXVII Congresso da Sociedade Brasileira de Computação, SBC, São Paulo, http://csbc2017.mackenzie.br/public/files/25-wei/9.pdf, Julho.

Brum et al. (2017) "Gamificação para o Ensino de Computação na Educação Básica", In: Anais do XXXVII Congresso da Sociedade Brasileira de Computação, SBC, São Paulo, http://csbc2017.mackenzie.br/public/files/25-wei/2.pdf, Julho.

Cordoni, T. (2016), Conhecendo as diferenças. Guia geração da Internet, São Paulo, p. 6-13, 2016.

Godinho et al. (2017) "Projeto Aprenda a Programar Jogando: Divulgando a Programação de Computadores para Crianças e Jovens", In: Anais do XXXVII Congresso da Sociedade Brasileira de Computação, SBC, São Paulo, http://csbc2017.mackenzie.br/public/files/25-wei/6.pdf, Julho.

Machado et al. (2010) "Uma Experiência em Escolas de Ensino Médio e Fundamental para a Descoberta de Jovens Talentos em Computação", In: Anais do XXX Congresso da Sociedade Brasileira de Computação, SBC, Belo Horizonte, http://www.inf.pucminas.br/sbc2010/anais/pdf/wei/st01_04.pdf, Julho.

Marques et al. (2017) "Pensar para Programar: Projeto de Ensino no Curso Técnico em Informática", In: Anais do XXXVII Congresso da Sociedade Brasileira de Computação, SBC, São Paulo, http://csbc2017.mackenzie.br/public/files/25wei/3.pdf, Julho. 